\title{
Minimal number of crossings in strong product of paths
}

\section{MARIÁN KLEŠČ, JANA PETRILlovÁ and MATÚŠ VAlO}

\section{ABSTRACT.}

The crossing number $\operatorname{cr}(G)$ of a graph $G$ is the minimal number of crossings over all drawings of $G$ in the plane. The exact crossing number is known only for few specific families of graphs. Cartesian products of two graphs belong to the first families of graphs for which the crossing number has been studied. Some results concerning crossing numbers are also known for join products of two graphs. In the paper, we start to collect the crossing numbers for the strong product of graphs, namely for the strong product of two paths.

\author{
DEPARTMENT OF MATHEMATICS AND THEORETICAL INFORMATICS \\ FACULTY OF ELECTRICAL ENGINEERING AND INFORMATICS \\ TECHNICAL UNIVERSITY OF KOŠICE \\ KOŠICE, SLOVAKIA \\ E-mail address: marian.klesc@tuke.sk \\ E-mail address: jana.petrillova@tuke.sk \\ E-mail address: matus.valo@tuke.sk
}

Received: 30.10.2011; In revised form: 01.11.2012; Accepted: 12.12 .2012

2010 Mathematics Subject Classification. 05C10, 05C38.

Key words and phrases. Cartesian product, strong product, crossing number, drawing, graph, path.

Corresponding author: Marián Klešč; marian.klesc@tuke.sk 